\title{
Naloxone induces copulation in control but not in prenatally stressed male rats
}

\author{
R. W. RHEES, D. S. BADGER, and D. E. FLEMING \\ Brigham Young University, Provo, Utah
}

\begin{abstract}
Pregnant rats were subjected to environmental stress (immobilization, illumination, heat) during the last trimester of gestation. Copulatory behavior of prenatally stressed and control male offspring was determined during seven weekly 30 -min tests. At the conclusion of the 7-week testing period, prenatally stressed and control males that were sexually inactive were injected intraperitoneally with $10 \mathrm{mg} / \mathrm{kg}$ of naloxone hydrochloride 30 -min prior to retesting for copulatory behavior. Fifty-five percent $(10 / 18)$ of the control males became sexually active and ejaculated during a single 30 -min testing period, whereas $0 \%(0 / 32)$ of the prenatally stressed males became sexually active. It is concluded that prenatal stress renders male offspring unresponsive to opiate-antagonist induction of copulatory behavior.
\end{abstract}

Several laboratories have implicated endogenous opiates in the regulation of masculine sexual behavior. For example, Meyerson and Terenius (1977) reported that $\beta$-endorphin treatment significantly decreased the percentage of male rats mounting receptive females and that the decreased mounting activity could be prevented by the opiate-antagonist naltrexone. Treatment with opiate-receptor antagonists has been shown to cause a significant reduction in the number of intromissions that precede ejaculation, a reduction in ejaculation latency, and an increase in the percentage of tests in which male rats ejaculated (Myers \& Baum, 1980). Gessa, Paglietti, and Pellegrini-Quarantotti (1979) reported that injection with the opiate antagonist naloxone induced copulatory behavior in sexually inactive male rats.

Studies have shown that prenatal stress in the form of restraint, high-level illumination, and heat, when applied to pregnant rats during the last trimester of gestation, significantly reduces normal copulatory behavior in male offspring (Rhees \& Fleming, 1981; Ward, 1972, 1977). We (Rhees \& Fleming, 1981) recently reported that only $12 \%$ of control male offspring failed to ejaculate in each of seven weekly mating tests, whereas $69 \%$ of prenatally stressed males failed to ejaculate. Prenatally stressed males that did not ejaculate (69\%) did not neck-bite, sniff the females' genitals, or attempt to mount. In addition to the decrease in sexual behavior, we have also observed recently that prenatal stress alters morphological development in the hypothalamus (Anderson, Rhees, \& Fleming, Note 1). The present

We gratefully acknowledge the gift of naloxone hydrochloride by Endo Laboratories. We thank S. Smith and E. Kinghorn for their technical assistance. This work was supported with funds provided by Brigham Young University College research grants. Address reprint requests to Reuben W. Rhees, Department of Zoology, Brigham Young University, Provo, Utah 84602. study was therefore designed to determine whether naloxone would induce copulatory behavior in sexually inactive prenatally stressed male rats, or whether the prenatal stress would render the animals unresponsive to opiate-antagonist induction.

\section{METHOD}

Subjects

Two groups of male Sprague-Dawley albino rats approximately 75 days of age at the beginning of the experiment were selected for study. A control group of 47 males was tested for mating vigor. Of this group, 18 animals were found to be noncopulators. This group of 18 males served as the control group for this study. The experimental group comprised 32 noncopulating animals from prenatally stressed mothers.

\section{Procedure}

The control and experimental groups were derived in the following manner. Nulliparous Sprague-Dawley female rats (Holtzman Co.) approximately 75 days of age were time-mated (plug date $=$ Day 0 of pregnancy) and randomly assigned to the control or the environmental-stress (immobilization, illumination, heat) group. Each group contained 15 pregnant animals. All animals were housed at $22^{\circ} \mathrm{C}$, had food and water available ad lib, and were under a reverse 12:12 light:dark cycle (photoperiod 2000 to $0800 \mathrm{~h}$ ). The control animals were not handled, except at their daily weighing. The animals in the environmentalstress group were subjected to stress three times daily during the last trimester of pregnancy (Ward, 1972). The stress was administered at 0900,1300 , and $1700 \mathrm{~h}$ daily. Each animal was placed in a $13 \times 6 \times 8 \mathrm{~cm}$ Plexiglas restraint chamber and subjected to $2,150-1 \mathrm{~m} / \mathrm{m}^{2}$ illumination for $45 \mathrm{~min}$. During illumination, the temperature in the chamber reached $31^{\circ} \mathrm{C}$. On the day of birth, live pups in each litter were counted and weighed. Litter size did not differ significantly between prenatally stressed and control litters. Offspring were sexed and weaned at 30 days of age and then housed two per cage. At 75 days of age, male offspring from each litter were tested for sexual behavior.

During the dark period of the diurnal cycle, male offspring were given 30-min tests for spontaneous sexual behavior toward ovariectomized females made receptive by hormonal injections $(0.1 \mathrm{mg}$ estradiol benzoate followed $42 \mathrm{~h}$ later by $1 \mathrm{mg}$ of progesterone). Females were placed into a mating arena $6 \mathrm{~h}$ after the progesterone injection. The males were placed into and 
allowed to adapt to the mating arena for $5 \mathrm{~min}$ before the receptive females were introduced. Testing was continued weekly for 7 weeks. The number of mounts, intromissions, and ejaculations were recorded. Upon conclusion of the seven weekly sexual-behavior tests, control and prenatally stressed inactive (no ejaculations) males were treated with a single injection of nalox one during the 8th week. Naloxone hydrochloride (Endo Laboratories) was prepared in a $0.9 \% \mathrm{NaCl}$ solution just prior to use. Each inactive male was injected intraperitoneally with $10 \mathrm{mg} / \mathrm{kg}$ of naloxone $30 \mathrm{~min}$ prior to being retested for copulatory behavior.

\section{Statistical Analysis}

Percentage data were analyzed with critical ratio (CR) techniques based on proportional statistics (McNemar, 1955).

\section{RESULTS}

In preliminary testing, the percentage of prenatally stressed males showing copulatory behavior was significantly reduced in comparison with that of control males. For example, the stressed offspring displayed significantly fewer mounts $(\mathrm{CR}=3.42, \mathrm{p}<.001)$, fewer intromissions $(C R=3.54, p<.001)$, and fewer ejaculations $(C R=3.93, p<.001)$ than did the control animals. These comparisons are presented in Table 1 .

The males that were sexually inactive (did not ejaculate) during the seven weekly tests (18/47 control animals; $32 / 44$ stressed animals) were selected for naloxone activation of sexual behavior. One week following the conclusion of the 7-week testing period, these animals were injected with naloxone and were returned to the testing arena. With naloxone treatment, 55\% $(10 / 18)$ of the sexually inactive control males ejaculated during the 30-min testing period. Some of these animals actually doubled the number of ejaculations normally

Table 1

Summary of Cumulative Mating Behavior Exhibited by Male Rats for the Seven Weekly Tests

\begin{tabular}{lcccc} 
& \multicolumn{4}{c}{ Percentage of Animals } \\
& Exhibiting at Least One \\
\cline { 2 - 5 } Male Offspring & N & $\begin{array}{c}\text { Mount- } \\
\text { ing }\end{array}$ & $\begin{array}{c}\text { Intro- } \\
\text { mission }\end{array}$ & $\begin{array}{c}\text { Ejacu- } \\
\text { lation }\end{array}$ \\
\hline Control & 47 & 72 & 64 & 62 \\
Prenatal Stress & 42 & $38^{*}$ & $29^{*}$ & $24^{*}$ \\
\hline
\end{tabular}

*Treatment means significantly different from control means $(p<.001)$.

Table 2

Effects of Naloxone Treatment $(10 \mathrm{mg} / \mathrm{kg})$ on Sexually Inactive Control and Prenatally Stressed Male Rats

\begin{tabular}{|c|c|c|c|c|}
\hline \multirow[b]{2}{*}{$\begin{array}{c}\text { Inactive Males From } \\
\text { Seven Weekly Tests } \\
\end{array}$} & \multicolumn{4}{|c|}{$\begin{array}{l}\text { Percentage of Animals } \\
\text { Exhibiting at Least One }\end{array}$} \\
\hline & $\mathrm{N}$ & $\begin{array}{l}\text { Mount- } \\
\text { ing }\end{array}$ & $\begin{array}{l}\text { Intro- } \\
\text { mission }\end{array}$ & $\begin{array}{l}\text { Ejacu- } \\
\text { lation }\end{array}$ \\
\hline Control & 18 & 61 & 61 & 55 \\
\hline Prenatal Stress & 32 & $0 *$ & $0^{*}$ & $0 *$ \\
\hline
\end{tabular}

*Differences between control and stressed groups not tested. seen with control animals in a $30-$ min testing period. On the other hand, none (0/32) of the stressed males ejaculated after treatment. Naloxone treatment failed completely to induce copulatory behavior in the experimental animals. Accordingly, CRs between the control and the stressed groups were not computed. The control and stressed animals that did not ejaculate following naloxone treatment did not attempt to mount, showed little interest in the female, and generally sat motionless during the testing period. These data are presented in Table 2.

\section{DISCUSSION}

These data support the results of other investigators that indicate that opiate antagonists facilitate or induce copulatory behavior in male rats (Myers \& Baum, 1980; PellegriniQuarantotti, Corda, Paglietti, Biggio, \& Gessa, 1978; PellegriniQuarantotti, Paglietti, Bonnani, Petta, \& Gessa, 1979; Sachs, Valcourt, \& Flagg, 1981). Gessa et al. (1979) reported that, of a group of sexually inactive males selected via five screening tests, $74 \%$ ejaculated following naloxone treatment. The figure of $55 \%$ ejaculations attained by the sexually inactive control animals in the present study compares favorably with the Gessa et al. data. Of particular interest is our observation that naloxone treatment failed to induce copulatory behavior in any of the sexually inactive prenatally stressed animals. These offspring were clearly insensitive to the activating effects of naloxone. Presumably, the neural substrate with which naloxone interacts to activate sexual behavior is nonfunctional in prenatally stressed male offspring.

Prenatal stress modifies sexually dimorphic brain development and thereby induces long-term behavioral aberrancy (see Rhees \& Fleming, 1981, Ward, 1972, 1977, and Anderson et al., Note 1). For example, it is clear that male offspring from stressed mothers not only have lower levels of male copulatory behavior (demasculinization) but also display higher levels of female lordotic behavior (feminization) than do male offspring from nonstressed mothers (Rhees \& Fleming, 1981; Ward, 1972, 1977). The demasculinizing effects of prenatal stress have also been corroborated by the present study (see Table 1). Furthermore, it has been observed recently that prenatal stress effectively alters the structural development of the sexually dimorphic nucleus of the preoptic area (SND-POA) of the hypothalamusthat is, the size of the SDN-POA of the male rat brain (Anderson et al. Note 1) is reduced.

Myers and Baum (1980) suggested that the facilitating effect of naloxone on masculine sexual response results, in part, from a drug-induced release of luteinizing hormone releasing hormone (LHRH). Accordingly, an increase in sexual activity induced by naloxone is ostensibly a hormone-mediated neuroendocrine response. That naloxone fails to induce sexual activity in prenatally stressed rats may be due to an aberrant development of brain centers that regulate gonadotropic hormone release. While the reasoning of Myers and Baum has been shown to be essentially incorrect by McConnell, Baum, and Badger (1981), it is apparent that naloxone does not activate brain centers that function to integrate the complex behavioral repertoire associated with sexual activity. Because hormonal imbalances in both maternal and fetal circulation are associated with prenatal stress (Tseu, 1981; Ward \& Weisz, 1980; Wilke, Tseu, Rhees, \& Fleming, 1982), and because modifications in SDN-POA anatomy also accompany maternal stress, a correlation between prenatal hormonal levels and changes in SDN-POA anatomy is implicated. This correlation may have a direct relationship to our observations in the present study. When naloxone is ineffective in activating sexual behavior, a defect in a functional brain system in which the SDN-POA may play a role is suggested. 


\section{REFERENCE NOTE}

1. Anderson, K., Rhees, R. W., \& Fleming, D. E. Effects of prenatal stress on differentiation of the sexually dimorphic nucleus of the preoptic area (SDN-POA) of the rat brain. Paper presented at the XIV Acta Endocrinological Congress, Stockholm, June 1983. (Manuscript submitted for publication, 1983.)

\section{REFERENCES}

Gessa, G. L., Paglietta, E., \& Pellegrini-Quarantotti, B. Induction of copulatory behavior in sexually inactive rats by naloxone. Science, 1979, 204, 203-205.

McConnell, S. K., BAUM, M. J., \& BADger, T. M. Lack of correlation between naloxone-induced changes in sexual behavior and serum LH in male rats. Hormones and Behavior, 1981, 15, 16-35.

McNemar, Q. Psychological statistics (2nd ed.). New York: Wiley, 1955.

Myers, B. M., \& BAUm, M. J. Facilitation of copulatory performance by naloxone: Effects of hypophysectomy, $17 \alpha$-estradiol, and luteinizing hormone releasing hormone. Pharmacology, Biochemistry and Behavior, 1980, 12, 365-370.

Myerson, B. J., \& Terenius, L. $\beta$-Endorphin and male sexual behavior. European Journal of Pharmacology, 1977, 42, 191-192.

Pellegrini-Quarantotti, B., Corda, M. G., Paglietti, E., Biggio, G., \& Gessa, G. L. Inhibition of copulatory behavior in male rats by D-ALA2-metenkephalinamide. Life Sciences, 1978, 23, 673-678.
Pellegrini-Quarantotti, B., Paglietti, E., Bonnani, A., Petta, M., \& Gessa, G. L. Naloxone shortens ejaculation latency in male rats. Experientia, 1979, 35, 524-525.

Rhees, R. W., \& Fleming, D. E. Effects of malnutrition, maternal stress, or ACTH injections during pregnancy on sexual behavior of male offspring. Physiology \& Behavior, 1981, 27, 879-882.

Sachs, B. D., Valcourt, R. J., \& FlagG, H. C. Copulatory behavior and sexual reflexes of male rats treated with naloxone. Pharmacology, Biochemistry and Behavior, 1981, 14, 251-253.

TSEU, S. R. Effects of prenatal stress on fetal and maternal corticosterone levels in the rat. Unpublished master's thesis, Brigham Young University, 1981.

WARD, I. L. Prenatal stress feminizes and demasculinizes the behavior of males. Science, 1972, 143, 212-213.

WARD, I. L. Sexual diversity. In J. D. Maser \& M. E. P. Seligman (Eds.), Psychopathology: Experimental models. San Francisco: Freeman, 1977.

WARD, I. L., \& WEisz, J. Maternal stress alters plasma testosterone in fetal males. Science, 1980, 207, 328-329.

Wilke, D. L., Tseu, S. R., Rhees, R. W., \& Fleming, D. E. Effects of environmental stress or ACTH treatment during pregnancy on maternal and fetal plasma androstenedione in the rat Hormones and Behavior, 1982, 16, 293-303.

(Manuscript received for publication August 15, 1983.) 